\title{
Case report: pulmonary soiling after one-lung ventilation with a bronchial blocker
}

\author{
[Observation : contamination pulmonaire à la suite de la ventilation unilatérale \\ avec un bloqueur bronchique]
}

Hee-Pyung Park MD, Jae-Hyon Bahk MD, Yong-Seok Oh MD, Byung-Moon Ham MD

Purpose: To report a case of pulmonary soiling of the dependent and of the non-dependent remaining lung when a Univent tube was used to achieve one-lung ventilation (OLV).

Clinical features: A 6 I-yr-old, I 58-cm, 6I-kg woman was scheduled for the resection of a lung cancer in the left lower lobe. An internal diameter 7.0-mm Univent tube was inserted under direct laryngoscopy and positioned via fibreoptic bronchoscopy. Prior to termination of OLV, there was no discharge through the blocker's lumen, aspirated just before deflating the cuff. As soon as the cuff was deflated, however, abundant blood-tinged secretions were aspirated. At the end of the operation, the chest radiograph showed haziness in the right upper lobe and in the remaining left upper lobe. The ineffective removal of secretions through the lumen of the blocker may be one of its main disadvantages. The bronchial blocker is always placed in the non-dependent bronchus for OLV, which may increase the probability of contaminating the dependent lung. Before deflating the blocker, we recommend the steep Trendelenburg position and the presence of a fibreoptic bronchoscope with a suction port at the tracheal carina to prevent overflow of secretions and soiling of the dependent lung.

Conclusion: Whenever a bronchial blocker is used for OLV, we should be cautious about the possibility that secretions accumulated distal to the blocker may contaminate the dependent or the non-dependent remaining lung.

Objectif : Présenter un cas de contamination pulmonaire du poumon déclive et de l'autre poumon restant, lors de l'utilisation d'un tube Univent assurant la ventilation unilatérale (VUL).

Éléments cliniques : Une femme de 61 ans, de $158 \mathrm{~cm}$ et $61 \mathrm{~kg}$, devait subir une intervention pour la résection d'un cancer du poumon au lobe inférieur gauche. Un tube Univent de 7,0 mm de diamètre a été inséré sous laryngoscopie directe et mis en place au moyen d'un bronchoscope flexible. Avant la fin de la VUL, aucun écoulement n'est apparu dans la lumière du tube bloqueur à la suite de l'aspiration réalisée juste avant de dégonfler le ballonnet. Mais aussitôt que le ballonnet a été dégonflé, d'abondantes sécrétions hémoptysiques ont été aspirées. Une radiographie pulmonaire réalisée à la fin de l'opération présentait des images floues du lobe supérieur droit et du lobe supérieur gauche restant. Le retrait inefficace des sécrétions au travers de la lumière du tube bloqueur pourrait être l'un de ces principaux inconvénients. Le bloqueur bronchique est toujours placé dans la bronche non déclive pour la VUL, ce qui peut augmenter la probabilité de contamination du poumon déclive. Nous recommandons de placer le patient en position de Trendelenburg et d'utiliser un fibroscope bronchique avec une ouverture d'aspiration au niveau de la carène trachéale, avant de dégonfler le ballonnet du bloqueur, afin de prévenir l'excès de sécrétions et la contamination du poumon déclive.

Conclusion : Toutes les fois que nous utilisons un bloqueur bronchique pour la VUL, nous devrions envisager la possibilité d'une accumulation de sécrétions, en aval du bloqueur, pouvant contaminer le poumon déclive et le restant du poumon non déclive.

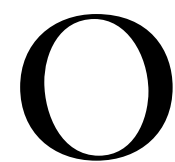

NE-LUNG ventilation (OLV) can be achieved with a double-lumen endobronchial tube (DLT) or a bronchial blocker. The main advantages of the Univent ${ }^{\circledR}$ tube (UT; Fuji Systems Corporation, Tokyo, Japan) over the DLT are its ease of placement in patients with a difficult airway ${ }^{1-3}$ and the absence of the need for tube exchange at the end of the procedure. ${ }^{4}$

The blocker of the UT differs from the bronchial tube and cuff of DLT, as it should always be placed in the non-dependent bronchus to achieve OLV. This may increase the probability of contaminating the

From the Department of Anesthesiology and Clinical Research Institute, Seoul National University Hospital, Seoul, Korea.

Address correspondence to: Dr. Jae-Hyon Bahk, Department of Anesthesiology and Clinical Research Institute, Seoul National University

Hospital, Seoul National University College of Medicine, 28 Yongon-Dong, Chongno-Gu, Seoul 110-744, Korea. Phone: 82-2-760-

2818; Fax: 82-2-747-5639; E-mail: bahkjh@plaza.snu.ac.kr

Support was provided solely from departmental sources.

Accepted for publication March 22, 2002.

Revision accepted June 10, 2002. 
dependent lung. The ability for suction through the narrow lumen of the blocker is limited. Therefore, when the seal is lost by withdrawal of the blocker into the trachea, or when the blocker is deflated at the end of the procedure, contamination of the dependent lung may result from blood or secretions, which stagnated distal to the blocker during surgery. In addition, overflow of secretions or inability to drain secretions may cause the non-dependent remaining lung on the side of operation to be soiled if the secretions cannot be adequately removed during surgery.

The risk of significant pulmonary contamination when using a bronchial blocker remains unclear. We present a case of pulmonary soiling following the termination of OLV via the UT, and discuss preventive measures.

\section{Clinical features}

A 61-yr-old, 158-cm, 61-kg woman was scheduled for the resection of a lung cancer in the left lower lobe. The patient had been in good health except for asthenia and weight loss, and mild cough and sputum; there was no smoking history. Physical examination was unremarkable. There was obstructive pneumonia in the superior segment of the left lower lobe on the preoperative computed tomography scan. On preoperative bronchoscopy, the left lower lobe bronchus was patent and the superior segment bronchus looked partially obstructed.

After the induction of anesthesia and muscle paralysis, an internal diameter $7.0 \mathrm{~mm}$ UT was inserted via direct laryngoscopy. Under direct vision through a fibreoptic bronchoscope (FOB), the blocker was advanced into the left main-stem bronchus so that the proximal part of the blocker balloon was located just below the tracheal carina. The placement of the blocker was re-checked after moving the patient to the right lateral decubitus position.

Surgery proceeded without incident for one hour and $45 \mathrm{~min}$ of OLV. At that time, percutaneous oxyhemoglobin saturation progressively decreased to $93 \%$ despite ventilation with $100 \%$ oxygen. Accordingly, a 5$\mathrm{cm} \mathrm{H}_{2} \mathrm{O}$ continuous positive airway pressure and a 5$\mathrm{cm} \mathrm{H}_{2} \mathrm{O}$ positive end-expiratory pressure were applied in the non-dependent and dependent lung respectively. Thereafter, the oxyhemoglobin saturation was maintained at $98-99 \%$. Prior to termination of OLV, no secretions could be aspirated through the blocker's lumen just before deflating the blocker's cuff. However, as soon as the blocker's cuff was deflated, copious blood-tinged secretions were observed at the proximal portion of the UT, and a gurgling sound was heard. To protect the dependent lung, OLV was temporarily resumed, and a suction catheter was inserted passed the UT for the removal of secretions. After removal of the suction catheter, suction was completed under visual guidance with the FOB to remove the remaining secretions. At the end of operation, the chest radiograph showed haziness in the right upper lobe and the remaining left upper lobe. The patient was transferred to the intensive care unit with the UT in situ for respiratory care. On the sixth postoperative day, she was extubated, transferred to a general ward and, thereafter, placed on long-term antibiotic therapy with pulmonary toilet. The final pathologic diagnosis was actinomycosis with abscess formation.

\section{Discussion}

Either DLT or a bronchial blocker can be used to achieve OLV during thoracotomy. However, there is some controversy as to which method provides the best operative condition. ${ }^{4,5}$ In our case, the UT was chosen because of the narrow margin of safety of right-sided DLT, an anatomical factor such as the unusually early take-off of the right upper lobe bronchus, and only the slight possibility of a sleeve resection of the left main bronchus.

The UT has several distinct limitations. The small lumen of the bronchial blocker results in slow inflation and deflation of the non-dependent lung, and the blocker lumen may be obstructed in the presence of blood and/or pus. ${ }^{6}$ Additionally, the blocker of the UT behaves as a high-pressure cuff when the intracuff volume is greater than $2 \mathrm{~mL}$ (the resting volume of the cuff). ${ }^{7}$ The ineffective removal of secretions through the narrow lumen of the blocker may be one of the most severe disadvantages, though high suction usually clears the lumen of these materials, and total blockage by inspissated secretions may be removed by a wire stylet. ${ }^{6}$ In terms of removing such secretions, DLT is superior to the UT because a suction catheter can be used through both the tracheal and bronchial lumens. In addition, a FOB can be passed freely through both lumens, so that information on the extent and exact location of secretions can be provided, and the secretions removed via the suction port of the FOB.

Contamination of the dependent lung by either blood or pus originating from the other lung usually results in severe massive atelectasis, pneumonia, or sepsis. ${ }^{6}$ When an embolectomy catheter or a bronchial blocker such as the UT and a commercial wire-guided endobronchial blocker ${ }^{8}$ is used for OLV, an absent or narrow lumen for removing secretions and its position in the non-dependent lung may lead to the contamination of the dependent lung. In this case, the blocker lumen was not an effective way of removing 
secretions. Thus, it is difficult to be confident that secretions are cleared before deflating the blocker. To avoid soiling the dependent lung, we recommend that the patient be placed in the steep Trendelenburg position to allow secretions to drain into the proximal part of the trachea, and a FOB with a suction port be positioned at the tracheal carina while slow deflation and re-inflation (if necessary) of the blocker is performed. To prevent secretions from soiling the remaining lung on the operative side, we may have to intermittently remove secretions using the same technique, or place a movable bronchial blocker more distally to create selective partial collapse (e.g., of a lobe). ${ }^{4}$

This report describes our experience of a case of pulmonary soiling in the dependent lung and the nondependent remaining lobe following the termination of OLV via the UT. We conclude that when a bronchial blocker is used for OLV, secretions may be difficult to remove effectively and that care should be taken to ensure that secretions accumulated distal to the blocker do not result in pulmonary contamination.

\section{References}

1 Ransom ES, Carter SL, Mund GD. Univent tube: a useful device in patients with difficult airways. J Cardiothorac Vasc Anesth 1995; 9: 725-7.

2 Gozal $\Upsilon$, Lee $W$. Nasal intubation and one-lung ventilation (Letter). Anesthesiology 1996; 84: 477.

3 Takenaka I, Aoyama K, Kadoya T. Use of the Univent bronchial-blocker tube for unanticipated difficult endotracheal intubation (Letter). Anesthesiology 2000; 93: 590-1.

4 Gayes JM. The Univent tube is the best technique for providing one-lung ventilation. Pro: one-lung ventilation is best accomplished with the Univent endotracheal tube. J Cardiothorac Vasc Anesth 1993; 7: 103-7.

5 Slinger $P$. The Univent tube is the best technique for providing one-lung ventilation. Con: the Univent tube is not the best method of providing one-lung ventilation. J Cardiothorac Vasc Anesth 1993; 7: 108-12.

6 Benumof JL. Separation of the two lungs (doublelumen tube and bronchial blocker intubation). In: Benumof JL (Ed.). Anesthesia for Thoracic Surgery, 2nd ed. Philadelphia: WB Saunders, 1995: 330-89.

7 Benumof JL, Gaughan SD, Ozaki G. The relationship among bronchial blocker cuff inflation volume, proximal airway pressure, and seal of the bronchial blocker cuff. J Cardiothorac Vasc Anesth 1992; 6: 404-8.

8 Arndt GA, Buchika S, Kranner PW, DeLessio ST. Wireguided endobronchial blockade in a patient with a limited mouth opening. Can J Anesth 1999; 46: 87-9. 